\title{
Downregulation of microRNA-605 indicates poor prognosis and promotes the progression of osteosarcoma
}

\author{
XIULING YI and CHUNLEI LIU \\ Department of Spinal Surgery, Weifang People's Hospital, Weifang, Shandong 261041, P.R. China
}

Received June 3, 2020; Accepted September 16, 2020

DOI: $10.3892 / \mathrm{ol} .2020 .12233$

\begin{abstract}
Osteosarcoma (OS) is a type of primary bone tumor, which is one of the leading causes of cancer-related death. MicroRNA (miR)-605 has been demonstrated to act as a prognostic biomarker and therapeutic target in various cancers, such as breast cancer and non-small cell lung cancer, but its function in OS remains unclear. The aim of the present study was to investigate the prognostic value of miR-605 in patients with OS by evaluating its expression levels and to explore the biological function of miR-605 in OS progression. For this purpose, tumor tissues and adjacent normal tissues were collected from OS patients, and the expression of miR-605 in the collected tissues and OS MG63, U2OS, HOS, and SAOS-2 cell lines was detected by quantitative real-time PCR. The prognostic value of miR-605 was evaluated by Kaplan-Meier survival curves and Cox regression analysis. The effects of miR-605 on OS cell proliferation, migration and invasion were analyzed by the CCK- 8 and transwell assays, respectively. The results of the present study revealed that miR-605 was significantly downregulated in OS tissues compared with adjacent normal tissues, which was associated with the clinical stage and distant metastasis of patients. Additionally, the downregulation of miR- 605 predicted the poor prognosis of patients with OS and served as an independent prognostic indicator. The downregulation of miR-605 enhanced cell proliferation, migration, and invasion of OS cells, which suggested that miR-605 may be involved in the progression of OS. The findings of the present study provide a new therapeutic target for the treatment of patients with OS.
\end{abstract}

\section{Introduction}

Osteosarcoma (OS) is an aggressive tumor of the bone that has a high level of chromosomal instability and very complex

Correspondence to: Dr Chunlei Liu, Department of Spinal Surgery, Weifang People's Hospital, 151 Guangwen Street, Weifang, Shandong 261041, P.R. China

E-mail: chunlei_spinal@163.com

Key words: osteosarcoma, microRNA-605, proliferation, migration, invasion, prognosis karyotypes $(1,2)$. Although extensive studies have been conducted on OS, the prognosis of OS remains unsatisfactory and OS remains a leading cause of tumor-related death $(3,4)$. Statistical data between 1994 and 2013 show that the wordwide 5-year survial rate of OS patients wihout metastasis is $\sim 70 \%$, but this rate in the patients with metastasis is $<20 \%$ (5). In recent decades, the 5-year overall survival rate of OS has improved significantly and a number of patients have died from local relapse or distant metastasis (6). Therefore, identifying a sensitive and effective biomarker that is involved in the progression of OS can help explore novel insights into the treatment of OS. Currently, the role of microRNAs (miRNAs), especially dysregulated miRNAs in the prognosis or diagnosis of tumors or cancers has attracted growing attention (7).

miRNAs are small endogenous non-coding RNAs with lengths of $\sim 18-21$ nucleotides (8). Previously, miRNAs have been demonstrated to regulate the expression of genes and mRNAs and the differentiation and apoptosis of cells by binding to the $3^{\prime}$ untranslated regions of their targets $(9,10)$. An increasing amount of evidence has revealed that miRNAs have functions in various cancers and tumors, such as serving as tumor suppressors or promoters. For example, miR-1285-5p acts as a tumor suppressor in breast cancer as it can inhibit the cell proliferation of breast cancer cells (11). In gastric cancer, miR-19a serves as a tumor promoter that facilitates cell growth and tumorigenesis (12). Previous studies also have investigated a variety of miRNAs that were associated with the progression of OS (13-15). miR-21 can inhibit the progression of OS by targeting reversion inducing cysteine rich protein with Kazal motifs, which regulates the Wnt/ $\beta$-catenin signaling pathway (16). miR-206 is upregulated in patients with OS compared to normal controls and induces the proliferation and migration of OS cells (17).

miR-605 has been reported to serve roles in non-small cell lung cancer, as cell proliferation and metastasis are inhibited by the downregulation of miR-605 (18). In prostate cancer, miR-605 is downregulated, which promotes the proliferation and invasion of prostate cancer by targeting engrailed-2 (EN2) (19). As miR-605 is downregulated in OS, it may be involved in the progression of OS (20). In the present study, the expression of miR-605 was investigated in OS tissues and cells using reverse transcription-quantitative (RT-q) PCR. The present study aimed to investigate the function of miR-605 in the progression and prognosis of OS to determine the potential therapeutic and prognostic value of miR-605 in OS. 


\section{Materials and methods}

Patients and tissue collection. A total of a 110 patients with OS that underwent resection surgery in Weifang People's Hospital (Weifang, China) from April 2009 to August 2014 were recruited in the present study. OS tissues and adjacent normal tissues $(5 \mathrm{~cm}$ from the edge of the tumor) were collected during the surgery and immediately frozen in liquid nitrogen at $-80^{\circ} \mathrm{C}$ for the following experiments. The inclusion criteria of patients were as follows: i) None of the patients had received any antitumor therapy, such as radiotherapy or chemotherapy; ii) patients had complete clinicopathological data. The exclusion criteria were as follows: i) Patients with severe organ dysfunction and injury; ii) patients who were not willing to partipate in this study. The clinicopathological features of the patients were summarized in Table I. There were 62 males and 48 females in the OS patients, and the average age of patients was $19.84 \pm 12.69$ years. The clinical stage of the tumor tissues was determined using the criteria by the Musculoskeletal Tumor Society system (21), and 72 patients had I-IIA stage tumors, whereas 38 patients had IIB-III stage tumors. A 5-year follow-up survey was performed by telephone to obtain the survival information of patients. The present study was approved by the Ethics Committee of Weifang People's Hospital (Weifang, China) with the approval no. WFRM01-082009, and all the patients signed informed consent for tissue use and analysis.

Cell lines and cell transfection. OS cell lines (MG63, U2OS, HOS, and SAOS-2) and the normal cell line hFOB 1.19 were purchased from the American Type Culture Collection. hFOB 1.19 cells were cultured in Dulbecco's Modified Eagle's medium (DMEM)/F-12 (1:1; Invitrogen; Thermo Fisher Scientific, Inc.) and osteosarcoma cells in DMEM (Invitrogen; Thermo Fisher Scientific, Inc.). All cells were maintained at $37^{\circ} \mathrm{C}$ in a humidified incubator with $5 \% \mathrm{CO}_{2}$ in media supplemented with $10 \%$ fetal bovine serum (FBS; Invitrogen; Thermo Fisher Scientific, Inc.), $1 \%$ of $100 \mathrm{U} / \mathrm{ml}$ penicillin and streptomycin (both Invitrogen; Thermo Fisher Scientific, Inc.) and $2 \mathrm{mM}$ L-glutamine (Gibco, Thermo Fisher Scientific, Inc.).

Cells were transfected with miR-605 mimic $(50 \mathrm{nM})$, miR-605 inhibitor (100 $\mathrm{nM}$ ), mimic negative control (mimic $\mathrm{NC} ; 50 \mathrm{nM}$ ) and inhibitor negative control (inhibitor NC; $100 \mathrm{nM}$ ), in order to regulate the expression of miR-605. The sequences for cell transfection were as follows: miR-605 mimic 5'-UAAAUCCCAUGGUGCCUUCUCCU-3'; miR-605 inhibitor 5'-AGGAGAAGGCACCAUGGGAUUUA-3'; mimic NC 5'-UUCUCCGAACGUGUCACGU-3'; and inhibitor NC 5'-CAGUACUUUUGUGUAGUACAA-3'. All the sequences were synthesized by Shanghai GenePharma Co, Ltd. Cell transfection was performed using Lipofectamine $2000^{\circledR}$ reagent (Invitrogen; Thermo Fisher Scientific, Inc.) at $37^{\circ} \mathrm{C}$ for $6 \mathrm{~h}$ according to the manufacturer's instructions. After that, the culture medium was replaced, and the subsequent experiments were carried out at $48 \mathrm{~h}$ post-transfection.

$R N A$ isolation and reverse transcription-quantitative PCR $(R T-q P C R)$. Total RNA was isolated from the collected tisues and OS cell lines using TRIzol ${ }^{\circledR}$ reagent (Invitrogen; Thermo Fisher Scientific, Inc.) and miRNeasy Mini kit (Qiagen, Inc.) according to the manufacturer's instructions. Then cDNA was synthesized using TaqMan MicroRNA Reverse Transcription kit (Applied Biosystems; Thermo Fisher Scientific, Inc.) and the following temperature protocol: $42^{\circ} \mathrm{C}$ for $30 \mathrm{~min}$ and $85^{\circ} \mathrm{C}$ for $5 \mathrm{sec}$. RT-qPCR was performed using the SYBR-Green I Master Mix kit (Invitrogen; Thermo Fisher Scientific, Inc.) with U6 as the internal control. The thermocycling conditions were as follows: $95^{\circ} \mathrm{C}$ for $10 \mathrm{~min}, 95^{\circ} \mathrm{C}$ for $20 \mathrm{sec}, 60^{\circ} \mathrm{C}$ for $15 \mathrm{sec}, 72^{\circ} \mathrm{C}$ for $20 \mathrm{sec}$, a total of 40 cycles. Following were the sequences of primers: miR-605 forward 5'-GCCGAGTAA ATCCCATGGTG-3', and reverse 5'-CTCAACTGGTGTCGT GGA-3'; U6 forward 5'-CTCGCTTCGGCAGCACA-3' and reverse 5'-AACGCTTCACGAATTTGCGT-3'. The $2^{-\Delta \Delta C q}$ method (22) was used to calculate the relative quantitation of miRNA expression.

Cell counting kit-8 (CCK-8) assay. Cell proliferation of OS was assessed by the CCK- 8 assay. Briefly, MG63 and U2OS cells with a density of $5 \times 10^{3}$ cells/well were seeded into 96-well plates and incubated for $0,24,48$ and $72 \mathrm{~h}$ at $37^{\circ} \mathrm{C}$. After the incubation, $10 \mu \mathrm{l}$ of CCK-8 reagent (Sigma-Aldrich; Merck KGaA) was added to each well for $4 \mathrm{~h}$ at $37^{\circ} \mathrm{C}$ with $5 \% \mathrm{CO}_{2}$. The absorbance at $450 \mathrm{~nm}$ was measured to evaluate the proliferation of OS cells.

Transwell assay. Transwell insert chambers (Corning, Inc.) with $8-\mu \mathrm{m}$ pores were used to evaluate the migration and invasion of MG63 and U2OS cells. A concentration of $1 \times 10^{4}$ cell/well cells were seeded into the upper chambers with serum-free DMEM and DMEM with 10\% FBS was contained in the lower chamber as chemoattractant. Following $24 \mathrm{~h}$ of incubation at $37^{\circ} \mathrm{C}$, cells migrated to the lower chamber were fixed in $70 \%$ ethanol for $30 \mathrm{~min}$ and stained with $0.2 \%$ crystal violet at room temperature for $10 \mathrm{~min}$. For invasion assay, the upper chambers were pre-coated with Matrigel (BD Biosciences) for $6 \mathrm{~h}$ at $37^{\circ} \mathrm{C}$. Stained cells were counted under a light microscope using a 200 magnification.

Statistical analysis. All data was collected from at least 3 independent replicates and were represented as mean value \pm standard deviation (SD). Data analysis was performed using SPSS 20.0 software (IBM Corp.) and GraphPad Prism 5.0 software (GraphPad Software, Inc.). Differences between two groups were analyzed using the paired Student's t-test and multiple groups by one-way ANOVA followed by the post hoc Tukey's test. The association of miR-605 with the clinicopathological features of the patients was assessed using $\chi^{2}$ test. Kaplan-Meier analysis with the log-rank test and multivariate Cox regression analysis were used to assess the prognostic value of miR-605. $\mathrm{P}<0.05$ was considered to indicate a statistically significant difference.

\section{Results}

miR-605 expression is downregulated in OS tissues and cell lines compared with normal tissues and cells. miR-605 expression in tissues from patients with OS and cell lines was detected by RT-qPCR. miR-605 was significantly downregulated in OS tissues compared with adjacent normal tissues $(\mathrm{P}<0.001$; Fig. 1A). Similarly, in OS cell lines, the 
Table I. Association between miR-605 expression and clinical features in patients with OS.

\begin{tabular}{|c|c|c|c|c|}
\hline Parameters & No. of cases $(n=110)$ & miR-605 low $(n=60)$ & miR-605 high $(n=50)$ & P-value \\
\hline Sex & & & & 0.483 \\
\hline Male & 62 & 32 & 30 & \\
\hline Female & 48 & 28 & 20 & \\
\hline Age, years & & & & 0.423 \\
\hline$<20$ & 57 & 29 & 28 & \\
\hline$\geq 20$ & 53 & 31 & 22 & \\
\hline Anatomical location & & & & 0.175 \\
\hline Tibia/femur & 67 & 40 & 27 & \\
\hline Elsewhere & 43 & 20 & 23 & \\
\hline Tumor size, $\mathrm{cm}$ & & & & 0.117 \\
\hline$<8$ & 57 & 27 & 30 & \\
\hline$\geq 8$ & 53 & 33 & 20 & \\
\hline Clinical stage & & & & 0.012 \\
\hline I-IIA & 72 & 33 & 39 & \\
\hline IIB-III & 38 & 27 & 11 & \\
\hline Distant metatasis & & & & 0.006 \\
\hline Negative & 78 & 36 & 42 & \\
\hline Positive & 32 & 24 & 8 & \\
\hline
\end{tabular}

OS, osteosarcoma.
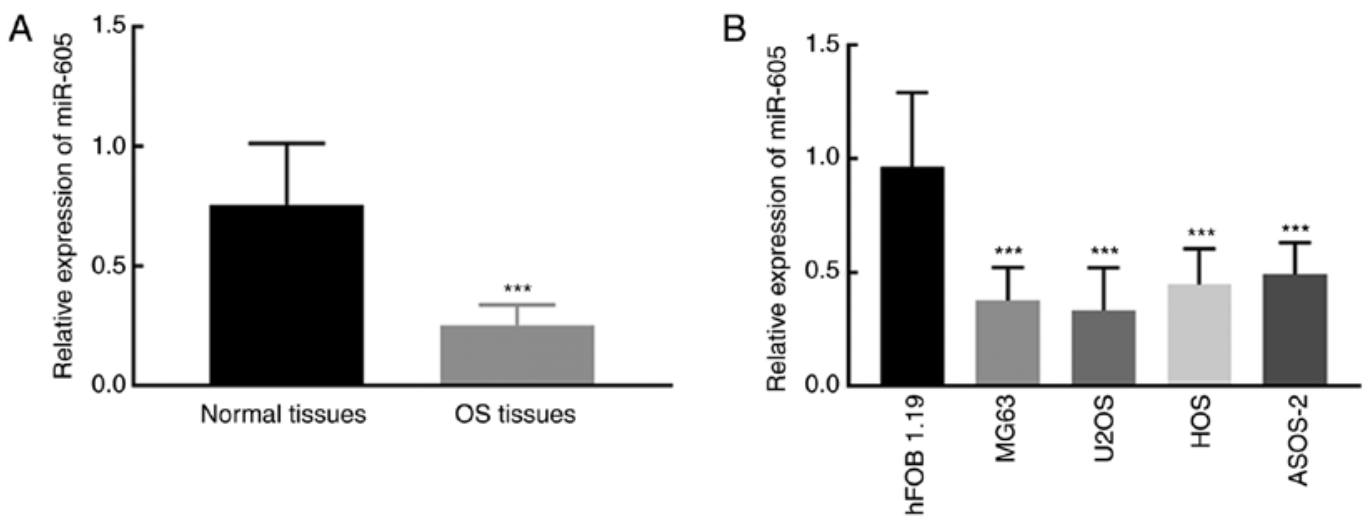

Figure 1. miR-605 expression measured by reverse transcription-quantitative PCR in OS tissues and cell lines. (A) miR-605 was significantly downregulated in OS tissues ( $\mathrm{n}=110)$ compared with adjacent normal tissues. (B) miR-605 was significantly downregulated in OS cells (MG63, U2OS, HOS and ASOS-2) compared with a normal cell line (hFOB 1.19). ${ }^{* * *} \mathrm{P}<0.001$. OS, osteosarcoma; miR, microRNA.

expression of miR-605 was significantly lower compared with that in the normal cell line hFOB 1.19 ( $\mathrm{P}<0.001$; Fig. 1B). Additionally, MG63 and U2OS were used for subsequent cell experimentation due to their relatively lower miR-605 expression among the four OS cell lines.

Relationship between miR-605 expression clinical features of patients with OS. Mean value of miR-605 mRNA expression (0.253) in tissues from patients with OS was used to divided 110 patients into the high miR-605 expression group $(n=50)$ and low miR-605 expression group $(n=60)$. The expression of miR-605 demonstrated significant association with the clinical stage $(\mathrm{P}=0.012)$ and distant metastasis $(\mathrm{P}=0.006)$ of patients with OS, while the age, sex, anatomical location and tumor size showed no significant relationship with miR-605 expression ( $\mathrm{P}>0.05$; Table I).

Prognostic value of miR-605. Kaplan-Meier curves demonstrated that patients with low miR-605 expression had a lower overall survival rate compared with patients with higher miR-605 expression ( $\log \operatorname{rank} \mathrm{P}=0.016$; Fig. 2). In addition, Cox regression analysis was used to evaluate the prognostic value of miR-605 and the clinical features of patients with OS. miR-605 expression was significantly associated with the overall survival rate of patients with OS (Fig. 2). In addition, the multivariate Cox regression analysis results indicated that 
Table II. Multivariate Cox regression analysis of clinical features and miR-605 in patients with OS.

\begin{tabular}{lccc}
\hline Indicators & HR & $95 \% \mathrm{CI}$ & P-value \\
\hline miR-605 & 2.533 & $1.150-6.107$ & 0.029 \\
Age & 1.187 & $0.582-2.420$ & 0.637 \\
Sex & 1.247 & $0.601-2.587$ & 0.553 \\
Anatomical location & 1.340 & $0.603-2.979$ & 0.473 \\
Tumor size & 1.787 & $0.812-3.932$ & 0.149 \\
Clinical stage & 1.896 & $1.055-3.885$ & 0.040 \\
Distant metastasis & 2.015 & $1.094-4.123$ & 0.036 \\
\hline
\end{tabular}

miR, microRNA; HR, hazard ratio; CI, confidence interval; OS, osteosarcoma.

miR-605 served as an independent factor in the prognosis of OS with the hazard ratio $(\mathrm{HR})=2.533 ; 95 \%$ confidence interval $(C I)=1.150-6.107 ; \mathrm{P}=0.029$; Table II).

Downregulation of miR-605 promotes cell proliferation in OS cells. MG63 and U2OS cells were transfected with miR-605 mimic or miR-605 inhibitor to overexpress or downregulate the expression of miR-605. RT-qPCR results demonstrated that miR-605 was significantly upregulated after transfection with miR-605 mimic, while the transfection with miR-605 inhibitor significantly downregulated the expression of miR-605 in both MG63 and U2OS cells ( $\mathrm{P}<0.001$; Fig. 3A). The proliferation of transfected cells was assessed using a CCK- 8 assay. It was found that the downregulation of miR-605 significantly promoted the proliferation of MG63 and U2OS cells, while the upregulation of miR-605 significantly inhibited the proliferation of MG63 and U2OS cells ( $\mathrm{P}<0.05$; Fig. 3B).

Effect of miR- 605 on OS cell migration and invasion. Transwell assays were used to evaluate the migration and invasion abilities of MG63 and U2OS cells. The migration ability of MG63 and U2OS cells was significantly inhibited by the overexpression of miR-605 but promoted by the downregulation of miR-605 $(\mathrm{P}<0.001$; Fig. 4A). For cell invasion, the knockdown of miR-605 significantly enhanced the invasion of MG63 and U2OS cells, while the overexpression of miR-605 inhibited OS cell invasion ( $\mathrm{P}<0.001$; Fig. 4B).

\section{Discussion}

With the development of molecular biology, an increasing number of biomarkers, such as miRNAs, that play roles in the progression of cancers and tumors have been identified, and the therapy of different cancers, including OS, has improved rapidly (23-25). miRNAs have been reported to play vital biomarker roles in various cancers, such as lung cancer, ovarian cancer, breast cancer, and gastric cancer (11,26-29). For example, miR-593 can inhibit the migration and invasion of non-small cell lung cancer cells by targeting SLUG-associated signaling pathways (30). miR-486 can promote the cell proliferation and mobility of renal cell carcinoma and inhibit its apoptosis (31). Several miRNAs have also been identified

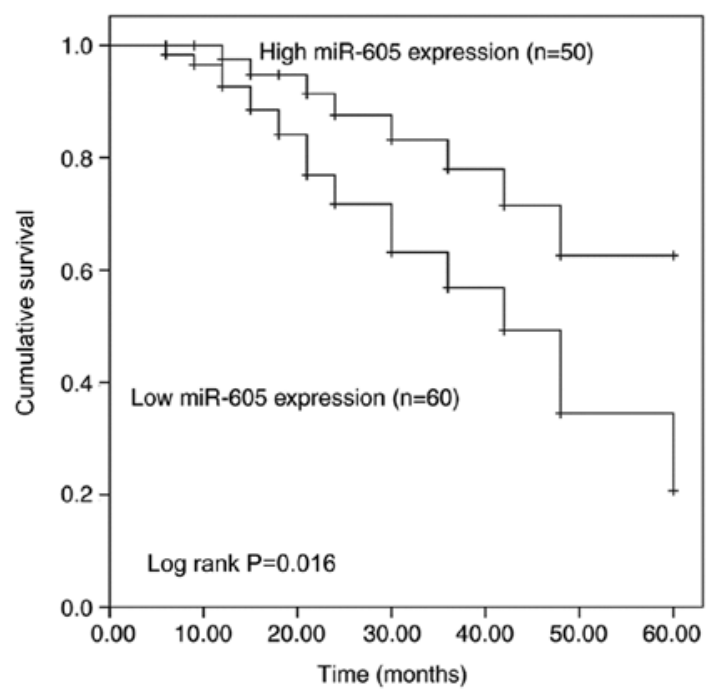

Figure 2. Kaplan-Meier overall survival curve of patients with high or low miR-605 expression. miR, microRNA.

as effective biomarkers for the prognosis and progression of OS $(32,33)$. miR-1225-5p serves as a tumor suppressor in OS and inhibits the proliferation, migration and invasion of OS cells by targeting Sox9 (32). miR-384 is downregulated in OS tissues and cells compared to normal controls and upregulates stem loop binding protein and promotes the growth and metastasis of OS (33). A previous study reported the downregulation of miR-605 in OS, which indicates that miR-605 may play a role in the progression of OS (20).

The present study demonstrated that miR-605 was significantly downregulated in OS tissues and cell lines compared with adjacent normal tissues and cells. Additionally, miR-605 expression was found to be associated with the clinical stage and distant metastasis of patients with OS in the present study. In terms of the prognosis of OS, patients with high miR-605 expression demonstrated an improved prognosis compared with patients with low miR-605 expression. In the present study, miR-605 was found to be an independent prognostic indicator of OS based on the results of Cox regression analysis. These findings of the present study revealed the potential prognostic biomarker role of miR-605 in OS, which is consistent with a previous study (12).

miR-605 is reported to play roles in the progression of numerous other cancers and tumors, where miR-605 is dysregulated and affects the proliferation, migration, invasion and apoptosis of tumor cells (34-36). For example, miR-605 inhibits the progression of intrahepatic cholangiocarcinoma by suppressing gankyrin (34). miR-605 also functions as a tumor suppressor in melanoma by regulating the expression of inositol polyphosphate-4-phosphatase type II B (35). In addition, miR-605 was also demonstrated to affect the proliferation, migration and invasion of non-small cell lung cancer, prostate cancer, and breast cancer $(18,19,36)$. In the present study, miR-605 was found to be a vital factor in the progression of OS, as the downregulation of miR-605 significantly promoted cell proliferation, migration, and invasion of OS, which indicates that miR-605 may be involved in the progression and development of OS. 

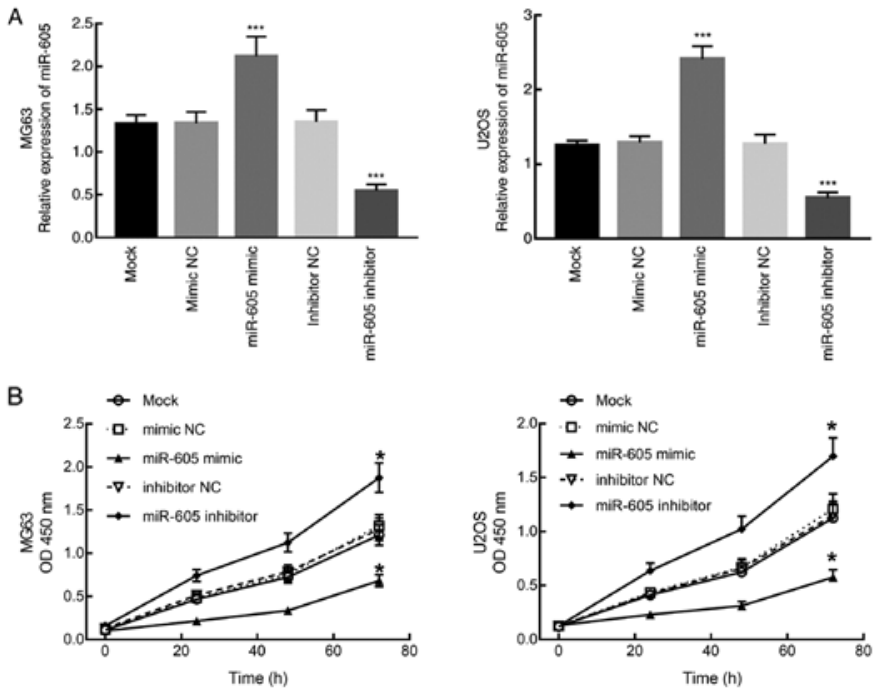

Figure 3. Effect of miR-605 expression on the proliferation of MG63 and U2OS cells. (A) miR-605 was significantly upregulated in MG63 and U2OS transfected with miR-605 mimic and downregulated in MG63 and U2OS cells transfected with miR-605 inhibitor. ${ }^{* * *} \mathrm{P}<0.001$. (B) The proliferation of MG63 and U2OS cells was significantly promoted by the downregulation of miR-605 and inhibited by the upregulation of miR-605. " $\mathrm{P}<0.05$. NC, negative control; miR, microRNA; OD, optical density; Mock, cells that only received transfection reagent.
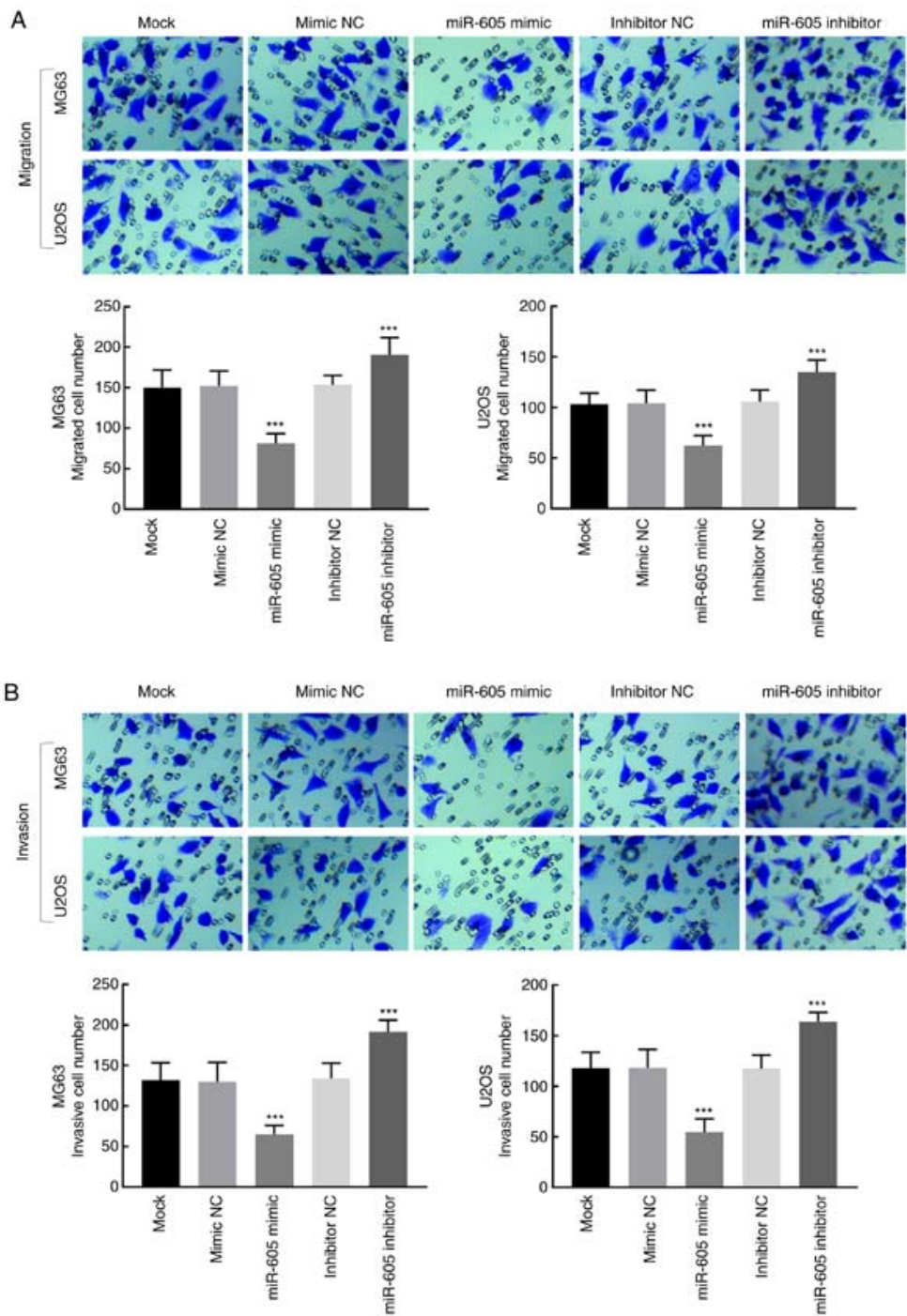

Figure 4. Effects of miR-605 expression on the migration and invasion of MG63 and U2OS cells. (A) Migration of MG63 and U2OS cells was significantly promoted by the downregulation of miR-605 and inhibited by the upregulation of miR-605. (B) Invasion of MG63 and U2OS was significantly promoted by the downregulation of miR-605 and inhibited by the upregulation of miR-605. ${ }^{* * *} \mathrm{P}<0.001$. NC, negative control; miR, microRNA; Mock, cells that only received transfection reagent. 
In the present study, the expression and function of miR-605 were investigated in OS tissues and cells in vitro, however, the role of miR-605 in the progression and prognosis of OS should be verified in in vivo experiments. On the other hand, previous studies have provided some potential targets of miR-605, such as tumor necrosis factor $\alpha$-induced protein 3, EN2, enhancer of zeste $2(\mathrm{EZH} 2)$ and forkhead Box P1, which mediate the functional effects of miR-605 in human malignancies $(18,19,37,38)$. EZH2 is a widely investigated oncogene in several human malignancies, such as non-small cell lung cancer and bladder cancer $(39,40)$. In OS tissues, EZH2 has been found to be upregulated and associated with aggressive tumor behavior and poor prognosis and the knockdown of EZH2 could significantly inhibit OS cell proliferation, migration and invasion (31). Thus, the functional role of miR-605 in OS progression may also be investigated by targeting EZH2. To corroborate this deduction, further mechanical studies and in vivo experiments are needed.

In conclusion, miR-605 is downregulated in OS and this dysregulation is associated with clinical stage and distant metastasis in patients with OS. The downregulation of miR-605 indicates a poor prognosis in terms of OS, which shows that miR-605 serves as an independent prognostic indicator for OS. In addition, the downregulation of miR-605 promotes OS cell proliferation, migration, and invasion, which suggests that miR-605 may be involved in the progression of OS. The present study provides a novel insight into the prognosis and progression of OS and provides new therapeutic targets for the treatment of patients with OS.

\section{Acknowledgements}

Not applicable.

\section{Funding}

No funding was received.

\section{Availability of data and material}

All the data analyzed in this study are included in this published article.

\section{Authors' contributions}

XY conducted the clinical study, analyzed clinical data and wrote the manuscript. CL designed this research and conducted the cell experiments. Both authors have read and approved this manuscript.

\section{Ethics approval and consent to participate}

The research was approved by the Ethics Committee of Weifang People's Hospital (Weifang, China) with the approval no. WFRM01-082009, and the participants provided signed informed consent for tissue collection and analysis.

\section{Consent for publication}

Consent for publication was obtained from the patients.

\section{Competing interests}

The authors declare that they have no competing interests.

\section{References}

1. Selvarajah S, Yoshimoto M, Ludkovski O, Park PC, Bayani J, Thorner P, Maire G, Squire JA and Zielenska M: Genomic signatures of chromosomal instability and osteosarcoma progression detected by high resolution array CGH and interphase FISH. Cytogenet Genome Res 122: 5-15, 2008.

2. Selvarajah S, Yoshimoto M, Maire G, Paderova J, Bayani J, Squire JA and Zielenska M: Identification of cryptic microaberrations in osteosarcoma by high-definition oligonucleotide array comparative genomic hybridization. Cancer Genet Cytogenet 179: 52-61, 2007.

3. Wang J, Liu S, Shi J, Li J, Wang S, Liu H, Zhao S, Duan K, Pan X and Yi Z: The role of miRNA in the diagnosis, prognosis, and treatment of osteosarcoma. Cancer Biother Radiopharm 34: 605-613, 2019.

4. Anderson ME: Update on survival in osteosarcoma. Orthop Clin North Am 47: 283-292, 2016.

5. Song K, Song J, Lin K, Chen F, Ma X, Jiang J and Li F: Survival analysis of patients with metastatic osteosarcoma: A Surveillance, Epidemiology, and End Results population-based study. Int Orthop 43: 1983-1991, 2019.

6. Ouyang L, Liu P, Yang S, Ye S, Xu W and Liu X: A three-plasma miRNA signature serves as novel biomarkers for osteosarcoma. Med Oncol 30: 340, 2013.

7. Zhang J, Yan YG, Wang C, Zhang SJ, Yu XH and Wang WJ: MicroRNAs in osteosarcoma. Clin Chim Acta 444: 9-17, 2015.

8. Hesse E and Taipaleenmäki H: MicroRNAs in bone metastasis. Curr Osteoporos Rep 17: 122-128, 2019.

9. Qu K, Wang Z, Lin XL, Zhang K, He XL and Zhang H: MicroRNAs: Key regulators of endothelial progenitor cell functions. Clin Chim Acta 448: 65-73, 2015.

10. Bartel DP: MicroRNAs: Genomics, biogenesis, mechanism, and function. Cell 116: 281-297, 2004.

11. Hironaka-Mitsuhashi A, Otsuka K, Gailhouste L, Sanchez Calle A, Kumazaki M, Yamamoto Y, Fujiwara Y and Ochiya T: miR-1285-5p/TMEM194A axis affects cell proliferation in breast cancer. Cancer Sci 111: 395-405, 2020.

12. Qin S, Ai F, Ji WF, Rao W, Zhang HC and Yao WJ: miR-19a promotes cell growth and tumorigenesis through targeting SOCS1 in gastric cancer. Asian Pac J Cancer Prev 14: 835-840, 2013.

13. Chen J and Chen Z: Downregulation of miR-19a inhibits the proliferation and promotes the apoptosis of osteosarcoma cells by regulating the JAK2/STAT3 pathway. Oncol Lett 20: 173, 2020.

14. Sun L, Wang L, Luan S, Jiang Y and Wang Q: miR-429 inhibits osteosarcoma progression by targeting HOXA9 through suppressing Wnt/ $\beta$-catenin signaling pathway. Oncol Lett 20: 2447-2455, 2020.

15. Yao J, Tan W, Wu W, Ye R, Li Y and Chen Y: Effects of miR-432 and $\mathrm{miR}-548 \mathrm{c}-3 \mathrm{p}$ on the proliferation and invasion of osteosarcoma cells. J BUON 25: 1562-1568, 2020.

16. Zhou L, Lu Y, Liu JS, Long SZ, Liu HL, Zhang J and Zhang T: The role of miR-21/RECK in the inhibition of osteosarcoma by curcumin. Mol Cell Probes 51: 101534, 2020.

17. Wang Y, Shi S, Zhang Q, Dong H and Zhang J: MicroRNA-206 upregulation relieves circTCF25-induced osteosarcoma cell proliferation and migration. J Cell Physiol jcp.29570, 2020.

18. Liao Y, Cao L, Wang F and Pang R: miR-605-5p promotes invasion and proliferation by targeting TNFAIP3 in non-small-cell lung cancer. J Cell Biochem 121: 779-787, 2020.

19. Zhou YJ, Yang HQ, Xia W, Cui L, Xu RF, Lu H, Xue Z, Zhang B, Tian ZN, Cao YJ, et al: Down-regulation of miR-605 promotes the proliferation and invasion of prostate cancer cells by up-regulating EN2. Life Sci 190: 7-14, 2017.

20. Zhang C, Wan J, Long F, Liu Q and He H: Identification and validation of microRNAs and their targets expressed in osteosarcoma. Oncol Lett 18: 5628-5636, 2019.

21. Cates JM: Comparison of the AJCC, MSTS, and modified spanier systems for clinical and pathologic staging of osteosarcoma. Am J Surg Pathol 41: 405-413, 2017.

22. Livak KJ and Schmittgen TD: Analysis of relative gene expression data using real-time quantitative PCR and the 2(-Delta Delta C(T)) Method. Methods 25: 402-408, 2001. 
23. Jia G, Wang Y, Yu Y, Li Z and Wang X: Long non coding RNA NR2F1 AS1 facilitates the osteosarcoma cell malignant phenotype via the miR 485 5p/miR 218 5p/BIRC5 axis. Oncol Rep 44: 1583-1595, 2020.

24. Fan H, Liu T, Tian $\mathrm{H}$ and Zhang S: TUSC8 inhibits the development of osteosarcoma by sponging miR 197 3p and targeting EHD2. Int J Mol Med 46: 1311-1320, 2020.

25. Wang L, Jiang J, Sun G, Zhang P and Li Y: Effects of lncRNA TUSC7 on the malignant biological behavior of osteosarcoma cells via regulation of miR-375. Oncol Lett 20: 133, 2020

26. Feliciano A, Garcia-Mayea Y, Jubierre L, Mir C, Hummel M, Castellvi J, Hernández-Losa J, Paciucci R, Sansano I, Sun Y, et al: miR-99a reveals two novel oncogenic proteins E2F2 and EMR2 and represses stemness in lung cancer. Cell Death Dis 8: e3141, 2017.

27. Zuberi M, Khan I, Mir R, Gandhi G, Ray PC and Saxena A: Utility of serum miR-125b as a diagnostic and prognostic indicator and its alliance with a panel of tumor suppressor genes in epithelial ovarian cancer. PLoS One 11: e0153902, 2016.

28. Mousa H, Yuan M, Zhang X, Li X, Shopit A, Almoiliqy M, Alshwmi M, Al-Dherasi A, Xu Y and Zuo Y: MicroRNA-4316 inhibits gastric cancer proliferation and migration via directly targeting VEGF-A. Cancer Cell Int 20: 62, 2020

29. Huang D, Sun W, Zhou Y, Li P, Chen F, Chen H, Xia D, Xu E Lai $\mathrm{M}, \mathrm{Wu}$ Y, et al: Mutations of key driver genes in colorectal cancer progression and metastasis. Cancer Metastasis Rev 37: 173-187, 2018.

30. Wei F, Wang M, Li Z, Wang Y and Zhou Y: miR 593 inhibits proliferation and invasion and promotes apoptosis in non small cell lung cancer cells by targeting SLUG associated signaling pathways. Mol Med Rep 20: 5172-5182, 2019.

31. Sun R, Shen J, Gao Y, Zhou Y, Yu Z, Hornicek F, Kan Q and Duan Z: Overexpression of EZH2 is associated with the poor prognosis in osteosarcoma and function analysis indicates a therapeutic potential. Oncotarget 7: 38333-38346, 2016.
32. Zhang W, Wei L, Sheng W, Kang B, Wang D and Zeng H: miR-1225-5p Functions as a tumor suppressor in osteosarcoma by targeting Sox9. DNA Cell Biol 39: 78-91, 2020.

33. Wang Y, Huang H and Li Y: Knocking down miR-384 promotes growth and metastasis of osteosarcoma MG63 cells by targeting SLBP. Artif Cells Nanomed Biotechnol 47: 1458-1465, 2019.

34. Li J, Tian F, Li D, Chen J, Jiang P, Zheng S, Li X and Wang S: miR-605 represses PSMD10/Gankyrin and inhibits intrahepatic cholangiocarcinoma cell progression. FEBS Lett 588: 3491-3500, 2014.

35. Chen L, Cao Y, Rong D, Wang Y and Cao Y: MicroRNA-605 functions as a tumor suppressor by targeting INPP4B in melanoma. Oncol Rep 38: 1276-1286, 2017.

36. Danesh H, Hashemi M, Bizhani F, Hashemi SM and Bahari G: Association study of miR-100, miR-124-1, miR-218-2, miR-301b, miR-605, and miR-4293 polymorphisms and the risk of breast cancer in a sample of Iranian population. Gene 647: 73-78, 2018.

37. Pan MZ, Song YL and Gao F: miR-605-3p inhibits malignant progression of prostate cancer by up-regulating EZH2. Eur Rev Med Pharmacol Sci 23: 8795-8805, 2019.

38. Zhou W and Li R: MicroRNA-605 inhibits the oncogenicity of non-small-cell lung cancer by directly targeting Forkhead Box P1. OncoTargets Ther 12: 3765-3777, 2019.

39. Qiu C, Li S, Sun D and Yang S: IncRNA PVT1 accelerates progression of non-small cell lung cancer via targeting miRNA-526b/EZH2 regulatory loop. Oncol Lett 19: 1267-1272, 2020.

40. Chen Z, Du Y, Liu X, Chen H, Weng X, Guo J, Wang M, Wang X and Wang L: EZH2 inhibition suppresses bladder cancer cell growth and metastasis via the JAK2/STAT3 signaling pathway. Oncol Lett 18: 907-915, 2019.

This work is licensed under a Creative Commons Attribution-NonCommercial-NoDerivatives 4.0 International (CC BY-NC-ND 4.0) License. 